\title{
BIAYA TRANSAKSI DAN ANALISIS KEUNTUNGAN PETANI PADA SISTEM RESI GUDANG KOPI ARABIKA GAYO DI KABUPATEN ACEH TENGAH
}

\author{
Keumala Fadhiela ${ }^{1}$, Dwi Rachmina ${ }^{2}$, dan Ratna Winandi ${ }^{3}$ \\ 1)Program Magister Sains Agribisnis, Sekolah Pascasarjana, Institut Pertanian Bogor \\ 2,3)Departemen Agrbisnis, Fakultas Ekonomi dan Manajemen, Institut Pertanian Bogor \\ e-mail : 1)keumala.fadhiela15@gmail.com
}

\begin{abstract}
The purpose of this study was to analyze the structure of transaction cost and analyze farmers profit on Arabica Gayo Coffee Warehouse Receipt System (WRS) in Central Aceh District. Transaction Costs Analysis (TCA) was used to analize transaction cost structure at selling delay activity and financing activity on WRS. While the ratio of transaction costs to farmers' profit was used to determine the level of effectiveness of WRS. The research was conducted at PT. Ketiara Warehouse, West Aceh district, Aceh. The selected samples were all 4o farmers of Arabica Gayo WRS in Central Aceh Regency. The highest transction cost was on delay selling activity (64.07\%) than transaction cost on warehouse receipt financing activity $(35.93 \%)$. Implementation of the warehouse receipt system in PT. Ketiara provided more benefits to the participants because average percentage ratio between the cost of the transaction with the benefit of $<10$ percent. Transaction costs and effectiveness of WRS need more attention and focus on the improvement of these two things to maximize the implementation and sustainability of Gayo Arabica Coffee WRS in Central Aceh District.
\end{abstract}

Keywords: delay selling, financing, transaction cost, warehouse receipt system.

\section{PENDAHULUAN}

Kementerian Perdagangan melalui Badan Pengawas Perdagangan Berjangka Komoditi (Bappebti) pada tahun 2008 membangun Sistem Resi Gudang (SRG) sebagai bentuk kepedulian pemerintah atas kebutuhan modal dan resiko yang dihadapi petani. Sistem Resi Gudang merupakan kelembagaan alternatif bagi petani karena menjadi instrumen manajemen resiko (tunda jual, lindung nilai dan jamin harga). Petani mendapatkan harga yang lebih baik karena menunda jual, mendapatkan kepastian kualitas dan kuantitas atas komoditas yang disimpan serta mendorong berusaha secara berkelompok sehingga memperkuat bargaining position petani. Selain menunda jual, petani juga mendapatkan manfaat pembiayaan melalui Resi Gudang yaitu 70 persen dari nilai barang yang disimpan. Resi Gudang bersifat negotiable (dapat diperdagangkan) dalam sistem pembiayaan perdagangan serta dapat dipergunakan sebagai jaminan (collateral) untuk memfasilitasi pemberian kredit (Bappebti, 2017). Tahun 2017, gudang SRG di Indoneia telah tersebar di 27 provinsi dan di 124 kabupaten yang terdiri dari 59 gudang swasta dan 127 gudang pemerintah (Bappebti, 2017).

Berdasarkan Peraturan Menteri Perdagangan Nomor 35 Tahun 2016, terdapat 14 komoditas yang dapat disimpan di SRG yaitu beras, jagung, gabah, kopi, kakao, lada, karet, rumput laut, rotan, garam, gambir, teh, kopra dan timah. Komoditas kopi memiliki jumlah penerbitan resi gudang ke empat terbanyak dibandingkan komoditas lainnya (Bappebti, 2016). Penghasil komoditas kopi arabika terbaik di Indonesia terdapat di Provinsi Aceh yaitu di Dataran Tinggi Gayo (DTG) yaitu Kabupaten Aceh Tengah, Kabupaten Bener Meriah, dan Kabupaten Gayo Lues. Adapun produksi kopi Arabika Gayo di ketiga daerah ini pada tahun 20152016 ditunjukkan pada Tabel 1. 
Tabel 1. Jumlah Produksi Kopi Arabika di Kabupaten Aceh Tengah, Kabupaten Bener Meriah, dan Kabupaten Gayo Lues tahun 2015-2016

\begin{tabular}{|c|c|c|c|}
\hline \multirow{2}{*}{ Tahun } & \multicolumn{3}{|c|}{ Produksi (ton) } \\
\cline { 2 - 4 } & Kab. Aceh Tengah & Kab. Bener Meriah & Kab. Gayo Lues \\
\hline 2014 & 26.851 & 11.029 & 1.063 \\
\hline 2015 & 29.239 & 11.526 & 1.082 \\
\hline
\end{tabular}

Sumber: BPS (2017)

Produksi kopi Arabika Gayo di Kabupaten Aceh Tengah lebih tinggi dari dua kabupaten lainnya. Namun penerbitan Resi Gudang kopi di Kabupaten Aceh Tengah (Tabel 2) relatif masih rendah yaitu hanya 0,15 persen dari total produksi kopi Arabika Gayo di Kabupaten Aceh Tengah pada tahun 2016 (BPS, 2017). Selain masih rendah, penerbitan Resi Gudang di Kabupaten Aceh Tengah juga berfluktasi. Padahal, SRG memberikan serangkaian manfaat untuk meningkatkan pendapatan petani karena menunda jual dan adanya pembiayaan (maksimal 70 persen) dari nilai barang yang disimpan.

Pembangunan SRG kopi di Kabupaten Aceh pertama kali dipelopori PT. Bandha Ghara Reksa (BGR) sejak tahun 2012. Namun tahun 2016 pemerintah Kabupaten Aceh Tengah menetapkan PT. Ketiara sebagai pengelola gudang SRG lokal yang menjalani segala proses mekanisme SRG yang ditetapkan oleh Bappebti. Berdasarkan hasil penelitian Tambarta (2017), fasilitas pergudangan kopi Arabika Gayo belum menunjang fasilitas informasi pasar, harga, produksi dan standardisasi yang memadai sehingga menyebabkan nilai tambah kopi sulit ditingkatkan dan sulit memotong peran dari tengkulak/pengijon. Petani lebih memilih mendapatkan pinjaman dari tengkulak dibandingkan pihak bank karena petani tidak memiliki aset tetap (fixed asset) yang dapat dijadikan agunan resmi sehingga hal ini dapat mempengaruhi posisi tawar petani (Juliaviani, 2016). Kondisi tersebut merupakan sebuah bentuk market failure yaitu kondisi dimana pasar mengalami kegagalan dalam menyediakan kebutuhan pasar secara efesien karena adanya informasi yang tidak lengkap atau asimetris serta sikap yang dapat menimbulkan suatu biaya transaksi.

Pada konsep New Institutional Economic, suatu kelembagaan bertujuan untuk menurunkan biaya transaksi melalui pengendalian perilaku oportunistik para pelaku pada pasar pertukaran. Kelembagaan sangat penting pada proses pertukaran karena sebagai aturan main (rule of the game) yang berkaitan dengan kerjasama dalam suatu sistem tata kelola (governance). Kerjasama juga memicu munculnya biaya transaksi karena kelembagaan memerlukan perlakuan khusus pada proses peningkatkan nilai tambah. Biaya transaksi muncul terutama pada mekanisme dan koordinasi antar pihak yang terlibat didalamnya. Berdasarkan hal tersebut, maka kelembagaan SRG dan biaya

Tabel 2. Rekapitulasi Transaksi Resi Gudang di SRG Kopi Arabika Kabupaten Aceh Tengah Tahun 2014-2017

\begin{tabular}{|c|c|c|c|c|}
\hline \multirow[b]{2}{*}{ Tahun } & \multicolumn{3}{|c|}{ Penerbitan } & \multirow{2}{*}{$\begin{array}{c}\text { Pembiayaan } \\
\text { Nilai (Miliar rupiah) }\end{array}$} \\
\hline & $\begin{array}{l}\text { Jumlah Resi } \\
\text { (lembar) }\end{array}$ & $\begin{array}{c}\text { Jumlah } \\
\text { Komoditi (ton) }\end{array}$ & $\begin{array}{l}\text { Nilai Barang } \\
\text { (Miliar rupiah) }\end{array}$ & \\
\hline 2014 & 1 & 5 & 0,2 & - \\
\hline 2015 & 13 & 440 & 26 & 15,4 \\
\hline 2016 & 2 & 50 & 3 & 2,1 \\
\hline 2017 & 6 & 90 & 5,8 & 3,8 \\
\hline 2018 & 4 & 40 & 3,6 & 2,5 \\
\hline
\end{tabular}

Sumber: Bappebti (2017) 
transaksi mempunyai kaitan yang erat. Sistem Resi Gudang merupakan salah satu model kelembagaan yang dirancang pemerintah dan diharapkan mampu menekan biaya transaksi. Semakin berfungsi suatu sistem kelembagaan maka kegitan transaksi semakin efesien sehingga biaya transaksi yang muncul rendah.

Menurut penelitian Masithoh (2016), biaya transaksi pada SRG gabah di Kabupaten Cianjur terdapat pada aktivitas pembiayaan dan aktivitas tunda jual. Biaya transaksi pada aktivitas pembiayaan SRG gabah lebih tinggi (65 persen) dari biaya transaksi pada aktivitas tunda jual (56 persen). Pada aktivitas pembiayaan SRG, biaya transaksi dapat memengaruhi pilihan (decision) petani untuk mengambil pembiayaan. Semakin kecil biaya transaksi maka permintaan pinjaman semakin besar (Abiad et al., 1988).

Jika biaya transaksi SRG tinggi, maka partisipasi petani yang bergabung rendah dan dipastikan SRG akan gagal meningkatkan kesejahteraan petani. Timbulnya biaya transaksi dapat membuat daya tawar petani justru semakin lemah dan memengaruhi minat petani untuk berpartisipasi di pasar pertukaran (Baye, 2010). Kurangnya minat para petani bergabung di SRG kopi di Kabupaten Aceh Tengah diduga karena adanya biaya transaksi. Padahal implementasi SRG diharapkan dapat meminimalisasi biaya transaksi yang muncul disetiap aktivitas baik pada aktivitas tunda jual maupun pembiayaan sehingga mengurangi resiko ketidakpastian pasar. Dengan demikian, proses transaksi, struktur biaya transaksi dan analisis keuntungan yang diperoleh petani SRG kopi Arabika Gayo di Kabupaten Aceh Tengah penting untuk diidentifikasi agar dapat menjadi masukan kebijakan untuk menciptakan transaksi yang efektif dan efesien pada pelaksanaan SRG.

\section{KERANGKA PEMIKIRAN}

Sistem Resi Gudang (SRG) memberikan dua manfaat pada petani yaitu sebagai wadah menunda jual komoditas pertanian dan sebagai lembaga yang memberikan akses pembiayaan. Melalui sistem tunda jual diharapkan petani memperoleh harga ekonomis atau harga layak untuk kelangsungan usahataninya. Konsep tunda jual pada kondisi keseimbangan (ekuilibrium) dijelaskan pada kurva permintaan dan penawaran sebagai berikut.

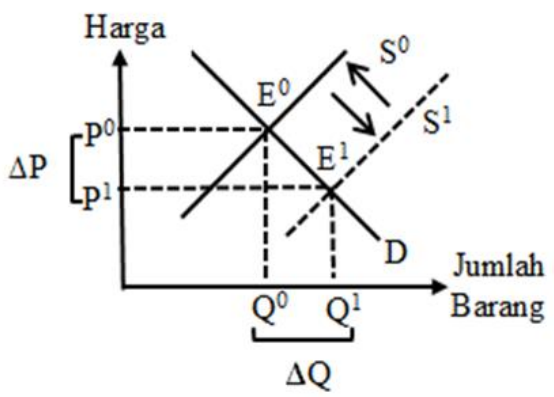

\section{Gambar 1. Kondisi Kurva Penawaran pada Saat Panen Raya Sumber: Boediono (2015)}

Kondisi penawaran komoditas pertanian yang melimpah pada saat panen raya mengakibatkan harga komoditas turun. Petani tidak memiliki pilihan lain selain menjual hasil panen raya saat itu juga. Kuantitas penawaran komoditas pertanian yang meningkat mengakibatkan kurva supply bergeser dari kurva $S^{0}$ menuju kurva $S^{1}$ dan kurva permintaan yang tidak berubah menyebabkan harga bergerak turun dari harga $\mathrm{P}^{0}$ menuju harga $\mathrm{P}^{1}$.

Harga yang turun ini dipandang terlalu rendah sehingga petani dirugikan. Oleh karena itu, pemerintah melalui instrumen tunda jual yang terdapat pada SRG memberikan solusi pada petani agar mendapatkan keuntungan yang layak. Pada saat panen raya, petani menyimpan hasil panennya di dalam gudang SRG, sehingga tidak adanya over supply. Hal ini ditunjukkan oleh kurva $S^{1}$ kembali bergeser ke kurva $\mathrm{S}^{0}$, harga $\mathrm{P}^{1}$ kembali bergerak naik ke harga $\mathrm{P}^{0}$ dan kembali lagi pada titik keseimbangan $\mathrm{E}^{0}$.

Tunda jual memperkuat daya tawarmenawar petani sehingga menciptakan efesiensi agribisnis karena petani dapat menunda penjualan komoditi setelah panen 
Tabel 3. Komponen Biaya Transaksi

\begin{tabular}{|c|c|}
\hline Komponen Transaksi & Keterangan \\
\hline Travel costac & $\begin{array}{l}\text { Biaya transportasi yang digunakan untuk melakukan seluruh } \\
\text { proses transaksi/pertukaran bisa berupa uang bensin (jika } \\
\text { memiliki kendaraan pribadi) maupun uang transportasi jika } \\
\text { menggunakan kendaraan umum }\end{array}$ \\
\hline Opportunity cost ${ }^{a}$ & $\begin{array}{l}\text { Biaya yang dikorbankan akibat meninggalkan pekerjaan utama } \\
\text { (non tunai) }\end{array}$ \\
\hline $\operatorname{Tax}^{a}$ & $\begin{array}{l}\text { Pajak dan materai (pajak tidak langsung untuk dokumen } \\
\text { transaksi) }\end{array}$ \\
\hline Communication cost ${ }^{b}$ & Biaya pulsa/komunikasi (upah perantara/fee trader), \\
\hline Paper cost ${ }^{a}$ & fotokopi/foto dan berkas/form (paper cost) \\
\hline
\end{tabular}

sambil menunggu harga kembali naik. Keuntungan yang diperoleh petani melalui aktivitas tunda jual SRG yaitu jika perubahan harga $\Delta \mathrm{P}$ lebih besar dari biaya penyimpanan SRG dan tergantung pada seberapa banyak jumlah barang yang disimpan di gudang SRG.

Menurut Coase (1937), biaya transaksi yakni biaya yang timbul dalam mengkoordinasikan aktivitas ekonomi yang menggunakan mekanisme harga. Biayabiaya yang dikeluarkan ini dapat berupa waktu maupun sumberdaya yang biasanya diukur/dikonversikan dengan satuan mata uang dalam melaksanakan suatu transaksi (pertukaran hak kepemilikan) yang berupa barang, jasa maupun hak intelektual. Biaya transaksi biasa terjadi dalam proses yang berulang (frequent) yang bersifat khusus (speciality) dengan kondisi pelaku usaha yang memiliki nalar yang terbatas (bounded rationality), dan biasanya pelaku usaha bersifat spekulatif (opportunist) Williamson (1989). Semakin tinggi biaya transaksi yang terjadi dalam kegiatan ekonomi (transaksi), berarti semakin tidak efisien kelembagaan yang terbentuk, demikian sebaliknya.

North dan Thomas (1973) mengklasifikasi biaya transaksi menjadi tiga jenis yaitu 1) Biaya pencarian (search cost) yaitu biaya untuk mendapatkan informasi tentang keuntungan atau kerugian suatu transaksi/ pertukaran, 2) Biaya negosiasi (negotiation cost) yaitu biaya merundingkan syarat-syarat suatu transaksi/pertukaran, dan 3) Biaya pelaksanaan (enforcement cost) yaitu biaya untuk melaksanakan suatu kontrak atau transaksi. Menurut Hosseini (2012), Furubotn dan Richer (2005) serta Jagwe (2011), komponen-komponen tersebut adalah travel cost, communication cost, paper cost, tax, dan opportunity cost seperti yang ditunjukkan pada Tabel 3.

Pada pelaksanaan SRG, partisipasi petani dapat dilakukan secara individu, dan dapat dilakukan secara kolektif melalui kelompok tani. Namun partisipasi melalui kelompok petani lebih direkomendasi karena dapat mempermudah proses penyimpanan komoditas hasil panen di SRG maupun pada proses mengakses pinjaman dari perbankan. Pelaksanaan kolektif (collective action) tersebut menurut Furubotn dan Richter (2005) merupakan salah satu bentuk dari aktivitas transaksi yang berbentuk investasi berupa modal sosial. Aktivitas tersebut diketahui mampu mengurangi biaya transaksi yang tercipta. Hal tersebut terjadi karena adanya semacam struktur sosial yang dapat membantu dalam mengurangi hambatan yang berupa ketidakpastian, informasi yang kompleks, dan rasionalitas yang terbatas dari berbagai pihak.

\section{METODE}

Pemilihan lokasi penelitian dilakukan dengan sengaja (purposive) dengan pertimbangan bahwa Kabupaten Aceh Tengah merupakan provinsi produsen kopi Arabika 
Gayo di Indonesia. Sistem Resi Gudang komoditi kopi Arabika Gayo di Kabupaten Aceh Tengah dipilih dengan pertimbangan SRG tersebut telah menerbitkan jumlah resi gudang komoditi kopi tertinggi hingga tahun 2017 di Provinsi Aceh. Pengumpulan data pada penelitian ini dilakukan pada bulan Februari-April 2018.

Jenis data yang digunakan dalam penelitian ini menggunakan data primer dan data sekunder. Data primer diperoleh dari hasil observasi dan wawancara langsung. Data sekunder diperoleh dari studi pustaka, internet, lembaga terkait seperti Bappebti, Dinas Perindustrian dan Perdagangan Provinsi Aceh, Dinas Perdagangan Kabupaten Aceh Tengah, Bank BRI Takengon dan PT. Ketiara selaku pengelola gudang. Sampel pada penelitian ini adalah seluruh petani yang bergabung di SRG kopi Arabika Gayo di Kabupaten Aceh Tengah. Sampel berjumlah 40 orang yang terdiri dari 5 kelompok tani yang telah menyimpan kopi ke gudang SRG pada periode tahun 2017.

\section{ANALISIS DATA}

\section{TRANSACTIONAL COST ANALYSIS (TCA) SRG}

Tahapan yang dilakukan untuk mengukur biaya transaksi adalah pertama melakukan perincian transaksi berdasarkan aktivitas utama SRG kemudian mengidentifikasi komponen biaya dari aktivitas tersebut. Aktivitas yang diteliti pada penelitian ini yaitu pada aktivitas transaksi tunda jual dan transaksi pembiayaan. Dari kedua aktivitas tersebut dijabarkan prosesproses transaksi berdasarkan teori dari North (1990) yaitu (1) biaya pencarian (search costs), (2) biaya negosasi (negotiation cost), dan (3) biaya pelaksanaan (enforcement cost).

Informasi proses transaksi SRG diperoleh berdasarkan SOP SRG dan informasi dari pengelola SRG yang kemudian dijadikan sebagai kerangka dasar penelusuran komponen SRG. Komponen yang digunakan untuk mengukur besaran biaya berdasarkan komponen pada Tabel 3 yang didapat dari hasil breakdown proses transaksi. Selanjutnya dilakukan pengukuran secara implist dan eksplisit baik berupa uang maupun waktu korbanan yang muncul. Nilai biaya transaksi yang muncul dianalisis dengan menggunakan model Transaction Cost Analysis (TCA). Adapun perhitungan total biaya transaksi biaya transaksi (TrC) menurut North dan Thomas (1973), sebagai berikut:

$\operatorname{TrC}=\sum \mathrm{Zij}$

Dimana:

$\operatorname{TrC}=$ Total biaya transaksi

$\mathrm{Zij}=$ Unit komponen biaya transaksi

Rasio merupakan pembagian antara masing-masing komponen biaya transaksi terhadap total biaya transaksi $(Z)$ dihitung dengan menggunakan rumus:

Rasio $\operatorname{TrC} / \operatorname{TrC} ; \sum \mathrm{Zij}=1$

Dimana:

$\mathrm{Zij}=$ Unit komponen biaya transaksi

$\operatorname{TrC}=$ Total biaya transaksi

\section{ANALISIS KEUNTUNGAN TUNDA JUAL SRG}

Manfaat yang diterima petani melalui aktivitas tunda jual diukur menggunakan indikator keuntungan melalui resi gudang yang diagunkan. Keuntungan tunda jual dirumuskan sebagai berikut.

$\mu \mathrm{SRG}=\mathrm{TR}-\mathrm{TC}$

Dimana:

$\mu=$ Keuntungan SRG

$\mathrm{TR}=$ Penerimaan dari selisih harga tunda jual SRG (Rp)

$\mathrm{TC}=$ Total biaya pelaksanaan tunda jual SRG (Rp)

$\mu S R G=(N K-N K o p)-(B P+B T)$

Dimana:

NK = Harga kontrak $(\mathrm{Rp} / \mathrm{kg})$

NKop = Harga kopi sebelum masuk gudang SRG $(\mathrm{Rp} / \mathrm{kg})$

BP = Biaya pelaksanaan SRG $(\mathrm{Rp} / \mathrm{kg})$

BT $=$ Biaya transaksi SRG $(\mathrm{Rp} / \mathrm{kg})$ 
Rasio digunakan untuk menunjukkan biaya transaksi yang tinggi belum tentu mengindikasikan bahwa petani rugi. Oleh karena itu rasio biaya transaksi terhadap keuntungan petani dipergunakan untuk menentukan tingkat efektifitas SRG. Rasio biaya transaksi dapat dihitung dengan menggunakan rumus berikut ini:

Rasio biaya transaksi $=\operatorname{TrC} / \mu \mathrm{SRG}$

Dimana:

$\begin{aligned} \operatorname{TrC}= & \text { Total biaya transaksi } \\ & \text { Rp/pelaksanaan kredit SRG) } \\ \mu S R G= & \begin{array}{l}\text { Keuntungan petani dari SRG } \\ (R p / \text { pelaksanaan SRG })\end{array}\end{aligned}$

\section{HASIL DAN PEMBAHASAN}

\section{STRUKTUR BIAYA TRANSAKSI AKTIVITAS TUNDA JUAL}

Aktivitas transaksi tunda jual adalah aktivitas yang berkaitan dengan proses menyimpan hasil panen hingga pada proses kepemilikan resi gudang. Aktivitas tunda jual berkaitan dengan beberapa lembagalembaga di dalam SRG seperti Lembaga Penguji Kesesuaian (LPK), Lembaga Asuransi dan Pusat Registrasi (Pusreg).

Pengujian uji mutu dilakukan oleh BPSMB di Kota Banda Aceh. Namun sejak tahun 2017, PT. Ketiara sebagai pengelola gudang juga dipercayakan oleh Bappebti sebagai lembaga resmi yang menguji fisik dan cita rasa untuk komoditas kopi di Kabupaten Aceh Tengah. Pengelola gudang berperan sangat penting karena menfasilitasi petani pada proses tunda jual. Biaya transaksi berdasarkan komponen pada aktivitas tunda jual pada SRG kopi Arabika Gayo di Kabupaten Aceh Tengah ditunjukkan pada Tabel 4.

Berdasarkan Tabel 4, biaya transaksi terbesar pada aktivitas transaksi tunda jual adalah travel cost dan opportunity cost yaitu masing-masing 41 persen. Travel cost merupakan biaya yang dikeluarkan petani berupa biaya bensin untuk perjalanan bolak balik melengkapi administrasi seluruh akti- vitas menerbitkan Resi Gudang. Sedangkan opportunity cost muncul karena petani mengorbankan pekerjaan yang lain berupa biaya non tunai karena transaksi dilakukan pada jam kerja sehingga petani harus mengeluarkan biaya korbanan (Masithoh, 2016). Opportunity cost dihitung berdasarkan waktu yang dihabiskan pada saat transaksi dan waktu perjalanan bolak balik yang dihabiskan petani dikali dengan biaya korbanan karena meninggalkan pekerjaan utama.

Tabel 4. Komponen Biaya Transaksi pada Aktivitas Tunda Jual SRG Kopi Arabika Gayo di Kabupaten Aceh Tengah

\begin{tabular}{|l|r|r|}
\hline $\begin{array}{c}\text { Komponen Biaya } \\
\text { Transaksi }\end{array}$ & $\begin{array}{c}\text { Nilai } \\
\text { (Rp/kg) }\end{array}$ & $\begin{array}{c}\text { Persentase } \\
\text { (\%) }\end{array}$ \\
\hline Travel cost & 23,71 & 41,10 \\
\hline Opportuniy cost & 23,67 & 41,00 \\
\hline Tax cost & 0,67 & 1,30 \\
\hline Communication & 8,84 & 15,30 \\
cost & 0,76 & 1,30 \\
\hline Paper cost & 57,74 & 100,00 \\
\hline Total & & \\
\hline
\end{tabular}

Travel cost dan opportunity cost merupakan biaya transaksi tertinggi yang timbul pada proses negosiasi. Adapun proses negosiasi pada aktivitas tunda jual yaitu berupa kesediaan waktu uji fisik dan cita rasa, kepengurusan administrasi menyimpan kopi ke pengelola gudang, kepengurusan pengesahan dari Dinas Perindustrian dan Perdagangan dan Koperasi (Disperindagkop) Kabupaten Aceh Tengah serta monitoring petani ke gudang SRG.

\section{STRUKTUR BIAYA TRANSAKSI AKTIVITAS PEMBIAYAAN}

Lembaga pembiayaan yang bekerja sama dengan SRG kopi di Kabupaten Aceh Tengah adalah Bank BRI Kantor Cabang Takengon. Pelaksanaan transaksi resi gudang hanya dapat dilakukan jika petani sudah memiliki dokumen resi gudang yang telah diterbitkan secara resmi oleh pengelola gudang. Berdasarkan Permenkeu No. 
171/PMK.05/2009 dan Permendag No. 66/MDAG/PER/12/2009 disebutkan bahwa petani, kelompok tani, gabungan kelompok tani, dan koperasi tani akan memperoleh pembiayaan dengan Bunga rendah yaitu 6 persen pertahun atau 0,5 persen ber bulan. Adapun komponen biaya transaksi yang dikeluarkan pada aktivitas pembiayaan ditunjukkan pada Tabel 5.

Tabel 5. Komponen Biaya Transaksi pada Aktivitas Pembiayaan SRG Kopi Arabika Gayo di Kabupaten Aceh Tengah

\begin{tabular}{|l|r|r|}
\hline $\begin{array}{c}\text { Komponen Biaya } \\
\text { Transaksi }\end{array}$ & $\begin{array}{c}\text { Nilai } \\
\text { (Rp/kg) }\end{array}$ & $\begin{array}{r}\text { Persentase } \\
\mathbf{( \% )}\end{array}$ \\
\hline Travel cost & 7,00 & 41,10 \\
\hline Opportuniy cost & 10,79 & 41,00 \\
\hline Tax cost & 0,76 & 1,30 \\
\hline Communication & 0,55 & 15,30 \\
\hline cost & 13,28 & 1,30 \\
\hline Paper cost & 32,38 & 100,00 \\
\hline Total & & \\
\hline
\end{tabular}

Komponen biaya transaksi terbesar yang dikeluarkan oleh petani SRG pada aktivitas pembiayaan adalah paper cost. Perhitungan paper cost yaitu dengan merincikan rata-rata biaya keperluan administrasi berupa biaya kertas, foto atau fotokopi yang harus ditanggung tiap petani berdasarkan harga yang berlaku. Biaya transaksi tersebut tinggi karena banyaknya berkas administrasi yang perlu dipenuhi untuk mengajukan kredit di bank. Adapun administrasi berupa paper cost pada aktivitas pembiayaan yaitu biaya foto, biaya fokotkopi KTP, biaya pembukaan buku tabungan, biaya scan dokumen Resi Gudang, biaya kertas surat pernyataan tidak sedang menerima kredit dan surat pernyataan berumur kurang dari 21 tahun, serta lampiran Rencana Definitif Kebutuhan Kredit (RDKK). Persyaratan tersebut wajib dilengkapi masing-masing petani untuk keterangan resmi bagi pihak bank bahwa telah melakukan kegiatan simpan komoditi di gudang SRG. Sedangkan komponen Communication cost adalah biaya transaksi yang rendah karena pada proses pembiayaan ini petani lebih banyak beraktivitas secara langsung ke bank dibandingkan menyelesaikan transaksi melalui handphone sehingga biaya pulsa yang dikeluarkan sangat kecil.

Struktur biaya transaksi pada Tabel 4 dan Tabel 5 menunjukkan bahwa biaya transaksi yang dikeluarkan petani pada aktivitas tunda jual lebih tinggi (64,07 persen) daripada aktivitas pembiayaan (35,93 persen). Pertama, hal ini dikarenakan beberapa aktivitas tunda jual berkaitan dengan proses tunda jual dan penerbitan Resi Gudang yang menjadi persyaratan utama untuk mendapatkan pembiayaan sebesar 70 persen dari nilai barang simpan. Kedua, komoditas kopi yang disimpan di SRG perlu melalui proses pengujian fisik dengan standar SNI dan cita rasa (cupping test) yang sangat ketat sehingga petani mengeluarkan biaya transaksi yang lebih tinggi terutama pada komponen travel cost. Proses ini yang membedakan komoditas kopi dengan komoditas lainnya yang dapat disimpan di gudang SRG. Adapun syarat kopi yang dapat dimpan di gudang SRG adalah kopi Arabika Gayo grade 1 dan grade 2 dengan kadar air $<14$ persen.

Hasil analisis struktrur biaya transaksi penelitian ini berbeda dengan hasil analisis biaya transaksi SRG gabah di Kabupaten Cianjur oleh Masithoh (2016) yang menyatakan bahwa biaya transaksi pada aktivitas transaksi pembiayaan (65 persen) lebih tinggi daripada pada aktivitas transaksi tunda jual (35 persen) karena kurangnya pemahaman petani terhadap kelengkapan administrasi pembiayaan sehingga petani harus berulang kali bolak-balik ke bank untuk menyelesaikan transaksi.

Komponen biaya transaksi berupa tax cost berupa materai tergolong kecil pada kedua aktivitas SRG karena merupakan biaya pajak tak langsung yang tidak diperlukan dalam jumlah yang banyak. Sedangkan komponen communication cost tertinggi terdapat pada proses pencarian informasi pada aktivitas tunda jual (Tabel 4) karena petani mengeluarkan biaya (searching information) seperti biaya pulsa yang digunakan untuk mencari informasi pasar 
dan menyimpan kopi, serta mengevaluasi pilihan menjual kopi. Namun berbeda pada aktivitas pembiayaan, communication cost justru sangat kecil (Tabel 5) disebabkan adanya penyampaian informasi satu arah dari ketua kelompok tani pada anggotanya sehingga petani tidak perlu bolak balik untuk melengkapi berkas administrasi pembiayaan ke bank.

Bank BRI Kabupaten Aceh Tengah sebagai lembaga pembiayaan mitra SRG sudah baik dalam hal melayani petani. Pihak bank melakukan pengecekan terlebih dahulu pada komoditas kopi yang masuk ke gudang SRG seperti kesediaan staple, posisi peletakan barang, dan kesesuain jumlah dan kualitas kopi. Pihak bank juga akan mengawasi tingkat keamanan kopi karena nilai kopi yang tinggi rentan terhadap pencurian.

\section{ANALISIS KEUNTUNGAN SISTEM RESI GUDANG}

Keefektifan SRG diukur dari keuntungan yang diperoleh petani dari selisih penerimaan harga jual-beli pada aktivitas tunda jual dan dari pembiayaan melalui jaminan Resi Gudang. Pengelola gudang menjalankan SRG dengan menggunakan model bisnis yang disebut sistem kontrak komoditi. Sistem kontrak komoditi yaitu kontrak pengelola gudang dengan standby buyer sehingga petani yang datang ke gudang bukan menjadi target consumer tapi menjadi partner penting bagi pengelola gudang. Oleh karena itu, besar kecilnya penerimaan petani dipengaruhi oleh harga kopi pasar dunia (dollar) yang telah disepakati dengan pihak buyer sesuai kontrak dan tergantung pada harga kopi pasar lokal yang berlaku saat sebelum masuk gudang. Sedangkan jangka waktu simpan kopi Arabika Gayo di gudang SRG biasanya 2 sampai 3 bulan.

Terdapat tiga alasan petani bergabung di SRG kopi Arabika Gayo. Pertama, keseluruhan petani (100 persen) termotivasi untuk mendapatkan pembiayaan sebesar 70 persen dari nilai barang yang disimpan. Kedua, sebanyak 70 persen petani ber- gabung karena kopi yang disimpan memiliki asuransi dan jaminan keamanan. Ketiga, 70 persen petani bergabung karena sudah memiliki kontrak penjualan kopi dengan buyer.

Keuntungan petani ikut serta pada SRG adalah berdasarkan keuntungan yang diperoleh petani dari selisih penerimaan aktivitas tunda jual dan total biaya-biaya pelaksanaan tunda jual SRG. Penerimaan aktivitas tunda jual petani dihitung dari selisih harga kontrak kopi dengan harga kopi sebelum masuk gudang SRG. Sedangkan biaya-biaya yang harus dikeluarkan petani meliputi biaya transaksi aktivitas tunda jual dan biaya transaksi aktivitas pembiayan serta biaya-biaya pelaksanaan SRG. Perhitungan keuntungan petani SRG kopi Arabika Gayo di Kabupaten Aceh Tengah ditunjukkan pada Tabel 6.

Pada Tabel 6 memperlihatkan keuntungan petani kopi SRG yang melakukan aktivitas tunda jual mendapatkan keuntungan lebih tinggi dibandingkan sebelum melakukan tunda jual. Hal ini menunjukkan bahwa aktivitas tunda jual memberikan manfaat peningkatan nilai jual bagi petani kopi di Kabupaten Aceh Tengah. Rata-rata harga dollar atas kopi kontrak yaitu US\$ 7,16 ( $\mathrm{Rp} 13.775,00 / \mathrm{kg}$ ). Harga kontrak ini merupakan harga yang diterima petani atas kontrak yang telah disepakati pengelola gudang dengan buyer. Kontrak komoditi karena petani memiliki ikatan dengan pengelola gudang sehingga memberikan kepastian pasar bagi petani. Sistem ini merupakan bentuk kontrak komoditi yang diterapkan pada SRG kopi Arabika Gayo di Kabupaten Aceh Tengah.

Nilai biaya transaksi masih dibawah 10 persen dari keuntungan yang diperoleh petani sehingga dapat diartikan bahwa biaya transaksi pada SRG kopi Arabika Gayo di Kabupaten Aceh Tengah masih digolongkan rendah. Rata-rata pinjaman petani berdasarkan jumlah kopi yang disimpan di gudang SRG adalah sebesar Rp 42.250,00/kg. Jumlah kredit tersebut masih dapat dibayar oleh 
Tabel 6. Rata-Rata Biaya Transaksi, Total Biaya, Penerimaan dan Keuntungan Petani SRG Kopi Arabika Gayo di Kabupaten Aceh Tengah

\begin{tabular}{|c|c|c|}
\hline Uraian & Satuan & Unit \\
\hline A. Volume kopi simpan & $\mathrm{kg}$ & $1.157,50$ \\
\hline B. Harga kopi saat masuk gudang & $\mathrm{Rp} / \mathrm{kg}$ & $65.000,00$ \\
\hline C. Nilai kopi saat masuk gudang $(\mathrm{AxB})$ & $\mathrm{Rp}$ & $75.237 .500,00$ \\
\hline D. Harga kontrak1) & $\mathrm{Rp} / \mathrm{kg}$ & $98.629,00$ \\
\hline E. Nilai kontrak (DxA) & $\mathrm{Rp}$ & $114.163 .067,00$ \\
\hline F. Pembiayaan²) & $\mathrm{Rp} / \mathrm{kg}$ & $42.250,00$ \\
\hline \multicolumn{3}{|l|}{ G. Biaya pelaksanaan } \\
\hline Biaya asuransi ${ }^{3)}$ & $\mathrm{Rp} / \mathrm{kg}$ & 65,00 \\
\hline Materai & $\mathrm{Rp} / \mathrm{kg}$ & 27,65 \\
\hline Biaya registrasi + ppn $10 \% 4)$ & $\mathrm{Rp} / \mathrm{kg}$ & 71,50 \\
\hline Bunga bank $k^{5}$ & $\mathrm{Rp} / \mathrm{kg} / 3$ bulan & 517,56 \\
\hline Biaya uji mutu & Sampel/kg & 172,79 \\
\hline Biaya handling (bongkar muat) & $\mathrm{Kg}$ & 80,00 \\
\hline Biaya transportasi ke gudang & $\mathrm{Kg}$ & 50,00 \\
\hline Biaya keamanan & $\mathrm{Rp} / \mathrm{kg} / 3$ bulan & 438,14 \\
\hline Biaya perawatan & $\mathrm{Rp} / \mathrm{kg} / 3$ bulan & 328,61 \\
\hline Biaya penyimpanan & $\mathrm{Rp} / \mathrm{kg} / 3$ bulan & 599,54 \\
\hline H. Biaya transaksi & $\mathrm{Rp} / \mathrm{kg}$ & 90,12 \\
\hline I. TC $(\mathrm{G}+\mathrm{H})$ & $\mathrm{Rp} / \mathrm{kg}$ & $2.440,90$ \\
\hline J. TR (D-B) & $\mathrm{Rp} / \mathrm{kg}$ & $33.629,00$ \\
\hline K. Profit (J-I) & $\mathrm{Rp} / \mathrm{kg}$ & $31.188,10$ \\
\hline $\begin{aligned} \text { Keterangan: } & \left.\text { 1)harga kontrak US\$ 7,16. }{ }^{2}\right) 65 \% \text { dari } \\
& \text { kopi, biaya ppn } 10 \% \text { dari biaya regis }\end{aligned}$ & $\begin{array}{l}0 \% \text { dari nilai kopi, } \\
\text { i pembiayaan }\end{array}$ & rasi $0,10 \%$ dari nilai \\
\hline
\end{tabular}

petani melalui keuntungan yang diperoleh dari pembiayaan SRG. Namun alokasi kredit yang diperoleh dan biaya konsumsi yang dikeluarkan masih digabung sehingga tidak adanya perincian yang jelas. Hal ini di khawatirkan pemanfaatan kredit tidak memberikan pengaruh yang signifikan pada peningkatan pendapatan (Ibrahim dan Bauer, 2013). Iski (2016) pada penelitiannya mengenai pengaruh kredit pada pendapatan petani kopi Arabika Gayo menjelaskan bahwa sebagian besar kredit digunakan untuk memenuhi kebutuhan konsumsi rumah tangga terutama kredit yang bersumber dari pedagang yaitu sebesar 84,75 persen.

Berdasarkan ketentuan dari Bappebti bahwa setiap petani hanya diperbolehkan menerima pinjaman dari bank melalui skema SRG yaitu $65 \%$ dari nilai barang (maksimal 75 juta per petani atau sebanyak 1.153,85 kg kopi). Meskipun demikian, kredit yang disubsidi pemerintah sebesar bunga bank 6 persen atau sebesar 0,5 persen per tahun masih dapat dibayar oleh petani responden melalui keuntungan yang diperoleh dari pembiayaan SRG. Hal ini membuktikan bahwa SRG di Kabupaten Aceh Tengah memberikan keuntungan yang besar bagi petani kopi karena permintaan kopi Arabika Gayo yang tinggi di pasar dunia dan adanya kepastian pembelian.

Rata-rata pendapatan yang diperoleh petani kopi Arabika Gayo penerima kredit dari koperasi yaitu sebesar Rp 20.658,46 $/ \mathrm{kg} / \mathrm{ha}$ dan pendapatan petani penerima kredit dari pedagang yaitu sebesar $\mathrm{Rp}$ $17.911,00 / \mathrm{kg} /$ ha (Iski, 2016). Ini menunjukkan bahwa kredit yang diperoleh dari lembaga pembiayaan formal meningkatkan penerimaan petani menjadi lebih tinggi daripada sumber pembiayaan yang diperoleh lembaga pembiayaan non formal (pedagang). Namun jika dibandingkan dengan keuntungan petani dari pelaksanaan SRG, pendapatan petani yang bergabung dari SRG lebih tinggi dari koperasi yaitu sebesar Rp 24.577,56/ha. Ini menunjukkan bahwa 
kredit yang diperoleh melalui pembiayaan Resi Gudang lebih dapat meningkatkan pendapatan petani kopi Arabika Gayo di Kabupaten Aceh Tengah daripada sumber pembiayaan dari koperasi maupun pedagang perantara.

Tak hanya keuntungan petani pada SRG kopi, pendapatan petani pada SRG padi juga lebih tinggi daripada pendapatan petani non SRG. Hasil penelitian Febrian (2011) tentang analisis pendapatan petani SRG padi di Kabupaten Indramayu menjelaskan bahwa pendapatan petani SRG padi sebesar $\mathrm{Rp}$ 9.815.895,51/ha sedangkan pendapatan petani yang tidak terlibat pada SRG sebesar Rp 6.864.010,22/ha. Meskipun pada penelitian tersebut tidak menganalisis penerimaan petani terhadap kredit SRG, namun dari hasil perhitungan analisis usahatani dapat disimpulkan pendapatan petani SRG lebih tinggi daripada petani yang tidak terlibat pada SRG.

\section{KESIMPULAN DAN SARAN}

\section{KESIMPULAN}

1. Biaya transaksi pada aktivitas tunda jual lebih tinggi (64,07 persen) daripada biaya transaksi pada aktivitas pembiayaan (35,93 persen). Biaya transaksi terbesar yang muncul pada aktivitas tunda jual yang yaitu travel cost dan opportunity cost.

2. Persentase rata-rata biaya transaksi dengan keuntungan yang diperoleh dari program SRG kopi Arabika Gayo adalah kurang dari 10 persen. Ini dapat disimpulkan bahwa biaya transaksi yang muncul pada aktivitas SRG sangat rendah dan tetap memberikan keuntungan yang tinggi bagi petani kopi.

\section{SARAN}

1. Sistem kontrak komoditi yang dijalankan pengelola gudang dan buyer diharapkan dapat terus berkesinambungan dan memberikan manfaat bagi seluruh petani kopi di Kabupaten Aceh Tengah.

2. Saran untuk penelitian selanjutnya dapat diidentifikasi lebih lanjut tentang pengaruh modal sosial terhadap biaya transaksi.

\section{DAFTAR PUSTAKA}

Abiad VG, Cuevas CE, Graham DH. 1988. Borrower Transaction Costs and Credit Rationing in Rural Financial Markets: The Philippine Case. Agricultural Credit Paper Counsil working paper. 8817(1988): 1-45.

Allen DW. 1991. What are Transaction Costs?. Research in Law and Economics 14: 1-18.

[BPS] Badan Pusat Statistik. Aceh Dalam Angka 2017. Aceh (ID): BPS.

Anggraini E. 2005. Analisis Biaya Transaksi dan Penerimaan Nelayan dan Petani di Pelabuhan Ratu Kabupaten Sukabumi [tesis]. Bogor (ID): Institut Pertanian Bogor.

[BAPPEBTI] Badan Pengawas Perdagangan Berjangka Komoditi. 2016. Perkembangan Jumlah Resi Gudang, Volume Komoditi, dan Nilai Resi Tahun 2008-2016. Jakarta (ID): BAPPEBTI

[BAPPEBTI] Badan Pengawas Perdagangan Berjangka Komoditi. 2017. Jumlah Komoditi Sistem Resi Gudang [Internet]. [diacu: 2017 April 5]. Tersedia dari http://www.BAPPEBTI.go.id/id/news

Baye MR. 2010. Managerial Economics and Business Strategy. New York (USA): Mc Graw Hill Companies, Inc.

Boediono. 2015. Pengantar Ilmu Ekonomi. Yogyakarta (ID): Fakultas Ekonomika dan Bisnis UGM.

Coase RH. 1937. The Nature of the Firm. Economica. 4(16): 386-405.

Febrian A. 2011. Analisis Pendapatan Usahatani Padi dengan Memanfaatkan Sistem Resi Gudang Studi Kasus Gapoktan Jaya Tani Indramayu [skripsi]. Bogor (ID): Institut Pertanian Bogor. 
Furubotn EG, Richter R. 2005. Institutions and Economic Theory: The Contribution of the New Institutional Economics (Second Edition). Michigan (US): The University Michigan Press.

Hosseini SS, Khaledi M, Ghorbani M, Brewin DG. 2012. An Analysis of Transaction Costs of Obtaining Credits in Rural Iran. J. Agr. Sci, Tech. 14(2012): 243-256.

Ibrahim AH, Bauer S. 2013. Access to Micro credit and its Impact on Farm Profit among Rural Farmers in Dryland of Sudan. Global Advanced Research. Journal of Agricultural Science. 2(3):088102.

Iski N. 2016. Pengaruh Kredit Terhadap Pendapatan Petani Kopi Arabika Organik di Provinsi Aceh [tesis]. Bogor (ID): Institut Pertanian Bogor.

Jagwe JN. 2011. The Impact of Transaction Costs on the Participation of Smallholder Farmers and Intermeiaries in the Banana Markets of Burundi, Democratic Republic of Congo and Rwanda [dissertation]. Pretoria [tZA]: University of Pretoria.

Juliaviani N. 2016. Analisis Efesiensi Pemasaran Ekspor Kopi Arabika Gayo di Provinsi Aceh [tesis]. Bogor (ID): Institut Pertanian Bogor.

Masithoh, D. 2016. Biaya Transaksi Sistem Resi Gudang Gabah [tesis]. Bogor (ID): Institut Pertanian Bogor.

Masuko L, Marufu D. 2003. The Determinants of Transactions Cost and Access to Credit by SMEs and the Poor in Zimbabwe. IFLIP Research Paper 03-9

North DC, RP Thomas. 1973. The Rise Of the Western World: New Economic History. Cambridge (UK): Cambridge University Press.

Tambarta, E. 2017. Analisis Nilai Tambah dan Strategi Pengembangan Olahan Kopi Arabika di Kabupaten Bener Meriah [tesis]. Bogor (ID): Institut Pertanian Bogor.
Williamson OE. 1989. Transaction Cost Economics: An Introduction. Handbook of Industrial Organization. 1(11). Elsevier Science Publishers B.V. University of California, Berkeley. 
